\title{
Acute toxicity of silver nitrate to in vitro fertilization of the sand dollar, Echinarachnius parma
}

\author{
Olivia Knight \\ This study was conducted under the supervision of Professor Todd Gillis, \\ Department of Integrative Biology, College of Biological Science \\ University of Guelph
}

\begin{abstract}
Considered one of the most toxic heavy metals, interest in silver (both ionic and bound forms) has increased over the past few years due to the production of consumer goods containing $\mathrm{Ag}^{+}$-releasing nanoparticles. Investigation into acceptable environmental limits has generated a substantial amount of evidence that even at very low concentrations, silver exposure is detrimental to organism health. This study employed the echinoderm fertilization assay to evaluate acute silver toxicity to a marine invertebrate, Echinarachnius parma. Gametes were procured from E. parma and fertilization success under control conditions was compared to that at varying treatment concentrations of silver nitrate. Exposure to silver nitrate significantly decreased percent fertilization in all treatment concentrations. Remarkably, at concentrations as low as $10^{-9} \mathrm{M} \mathrm{AgNO}_{3}$ percent fertilization decreased by $20-30 \%$ compared to the control. The results of this study are consistent with the existing literature, adding to the expanding collection of data that emphasizes the need for more stringent environmental silver regulation criteria in order to ensure the protection of aquatic ecosystems.
\end{abstract}

A

nthropogenic contamination of aquatic ecosystems through improper effluent disposal, spillages and emissions has generated a decline in water quality with negative consequences for a wide range of organisms $[1,2,3]$. Polychlorinated biphenyls, organochlorides, and heavy metals have been demonstrated to be detrimental to the health of aquatic environments and their inhabitants [2,3,4]. While naturally present in trace amounts, heavy metals may exist at elevated concentrations due to industrial activity $[5,6,7]$. A recent rise in manufacturing of medical and consumer products containing silver nanoparticles, which are designed to release $\mathrm{Ag}^{+}$ions as a disinfectant, raises new concerns about the toxicity of this metal [4]. Other silver containing compounds like silver nitrate, associated with electronic manufacturing and photo processing, are discharged into coastal waters and cause an accumulation of heavy metal ions in these areas $[2,4,5,7]$. While the literature is consistent in its assertion that excessive silver exposure is detrimental to the health of organisms at all life stages, the mechanism of silver toxicity in some organisms remains unclear $[1,4,5,7,8,9]$. Details of the underlying mode of action in marine organisms are particularly limited [5]. One proposed method of silver toxicity in marine teleosts is inhibition of $\mathrm{Na}^{+} / \mathrm{K}^{+}$ATPase at the gill epithelium, causing an influx of ions and eventually dehydration. Less still is known about the physiological impact of silver on marine invertebrates, but it has been suggested that silver may impair cell membrane function in a variety of tissues [5].
With the current EPA ambient water quality criteria for silver under review, an influx of new $\mathrm{Ag}^{+}$-releasing products on the market, and ambiguity surrounding its effects on marine organisms, silver toxicity warrants in depth evaluation $[8,9,10]$.

Echinoderms have often been employed as models to assess contaminant toxicity $[1,11,12]$. They are an ideal organism due to their abundance, sensitivity to changes in water chemistry, and easily procured gametes $[9,12]$. In particular, the echinoderm fertilization assay has been applied to numerous chemicals and effluents, where the impact of a contaminant on fertilization success is used as an indication of its toxicity $[7,12,13]$.

The purpose of this study is to examine the effect of ambient $\mathrm{Ag}^{+}$concentration on the fertilization success of Echinarachnius parma. Silver nitrate is considered one of the most toxic silver compounds because it readily dissociates in water, and is also a major cause of silver pollution in the environment, making in an optimal source of free ionic silver for this experiment [7,9,14]. Treatment concentration values were selected based on information regarding the current level of silver in the Atlantic Ocean $(\sim 0.7 \mathrm{pM}$ near the surface), the most recent draft marine water-quality criterion for silver $\left(\sim 8 \times 10^{-9} \mathrm{M}\right)$, and protocol from fertilization assays using similar subjects and contaminants $[1,5,7,15]$. By monitoring the number of zygotes formed in mediums containing five different concentrations of silver nitrate, this experiment tests the 
hypothesis that exposure to elevated ambient concentrations of $\mathrm{Ag}^{+}$will be detrimental to E. parma fertilization success. According to this hypothesis, a higher ambient concentration of silver nitrate should correspond to a lower percentage of E. parma zygotes.

\section{RESULTS AND DISCUSSION}

A negative trend was observed between mean percent fertilization and ambient concentration of $\mathrm{AgNO}_{3}$ (Fig. 1). Mean percent fertilization (number of zygotes out of 100 eggs) was observed to be $81.3 \% \pm 3.2$ under control conditions (Fig. 1). All other treatments had significantly lower mean percent fertilization than the control (Fig. 1; LSD, $\mathrm{p}<0.05$ ). In particular, mean percent fertilization of the $10^{-3} \mathrm{M} \mathrm{AgNO}_{3}$ treatment was $11.7 \% \pm 4.4$, significantly lower than any other treatment (Fig. 1; LSD, p<0.05). Mean percent fertilization at $10^{-5} \mathrm{M}, 10^{-7} \mathrm{M}$, and $10^{-9} \mathrm{M} \mathrm{AgNO}_{3}$ was very similar, at $52.3 \% \pm 2.6,49.3 \% \pm 2.6$, and $58.0 \% \pm$ 2.6 respectively. No significance was observed between these treatments (Fig. 1; LSD, $\mathrm{p}>0.05$ ).

All treatments demonstrated significantly lower mean percent fertilization than the control (23\%- 69\% lower), indicating that ionic silver has a substantial negative impact on E. parma fertilization even at very low concentrations (Fig. 1). Although the general trend supports the hypothesis, it does not illustrate a directly proportional relationship between concentration of silver and toxicity. As predicted, the highest concentration of ambient silver yielded lowest

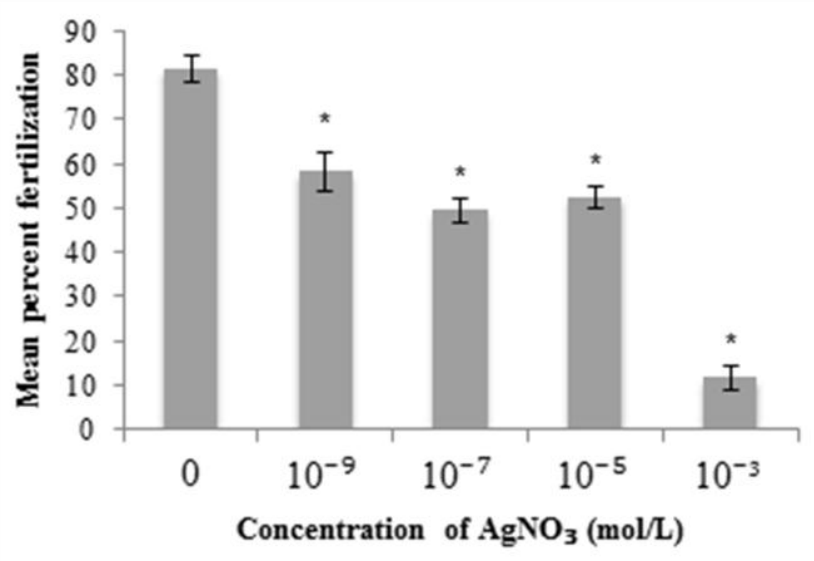

Fig. 1. Fertilization success in Echinarachnius parma decreases with exposure to increasing concentrations of silver nitrate. A general trend of decreasing mean percent fertilization with increasing concentration of silver nitrate is observed. Mean percent fertilization at $10^{-3} \mathrm{M} \mathrm{AgNO}_{3}$ is significantly lower than any other treatment $(\mathrm{LSD}, \mathrm{p}<0.05)$. No significant difference in fertilization was observed among the $10^{-5} \mathrm{M}, 10^{-7} \mathrm{M}$, and $10^{-9}$ $\mathrm{M} \mathrm{AgNO}_{3}$ treatment groups (LSD, $p>0.05$ ). Asterisks denote treatments significantly different than the control $(L S D, p<0.05)$. Error bars represent standard error. percent fertilization. However, mean fertilization in intermediate treatments at concentrations from $10^{-9} \mathrm{M}$ to $10^{-5} \mathrm{M}$ did not differ significantly from one another. The dramatic decrease in mean fertilization that occurred between $10^{-5} \mathrm{M}$ and $10^{-3} \mathrm{M} \mathrm{AgNO}_{3}$ alludes to the possibility of a threshold of silver tolerance between these concentrations. It may be that regulatory mechanisms of most eggs are able to compensate for elevated levels of silver up until some specific concentration between those two values; a greater understanding of the mechanism of silver toxicity in marine invertebrates would provide some insight into these speculations. Regardless of the specifics of trend mechanics or physiological mechanisms, it is apparent that the data conform to one critical aspect of the hypothesis: silver is toxic to the fertilization process.

The results of this study are consistent with the majority of the literature to date regarding both echinoderms and other species. A recent experiment examining the effects of silver exposure to zebrafish (Danio rerio) development found a significant increase in embryo mortality at concentrations equal to or greater than $3 \mu \mathrm{M}$ [4]. While Powers et al. did not look at effects of silver on fertilization processes, the lethal concentrations for embryos are comparable to the concentrations tested in this study. In addition, they found evidence that sub-lethal concentrations of silver resulted in neurological defects in later stages of development [4]. A study done by Naddy et al. in 2007 established that an ambient silver concentration of $35 \mu \mathrm{g} / \mathrm{L}$ had an $80 \%$ mortality rate for the cladoceran species Ceriodaphnia dubia, an aquatic invertebrate [8]. While it was not specifically looking at silver, an experiment by Gopalakrishnan et al. (2007) examining toxicity of heavy metals on the marine polychaete Hydroides elegans found that heavy metal exposure leads to fertilization block and arrested development [17]. Another study, by Ward et al. in 2006, investigated the chronic toxicity of silver to the sea urchin Arbacia punctulata and looked at effects on fertilization, embryonic viability and adult survival [7]. They found that percent fertilization decreased from $85.7 \% \pm 3.2$ under control conditions $(5.2 \mu \mathrm{g} / \mathrm{L})$ to roughly $6.3 \% \pm 3.2$ at 40 $\mu \mathrm{g} / \mathrm{L}$ (equivalent to roughly $4 \times 10^{-7} \mathrm{M}$ ). They also found that a concentration of $33 \mu \mathrm{g} / \mathrm{L}\left(\sim 3 \times 10^{-7} \mathrm{M}\right)$ caused $75 \%$ mortality after 30 days in adult urchins. Although $A$. punctulata appears to exhibit slightly greater sensitivity to silver than E. parma, their results are remarkably similar to the ones in this study and certainly the phylogenetic relatedness of the test species adds merit to the findings here.

A limitation of investigating effects of ionic silver on marine organisms is the tendency for silver to bind to other molecules in the seawater, such as chloride. This not only causes a discrepancy between concentration of silver nitrate and concentration of ionic silver, but also if a precipitate forms it may create a physical barrier, preventing sperm from reaching eggs and potentially confounding the results. In future experiments, it might be beneficial to measure free 
ionic silver in addition to the known concentration of silver nitrate, accounting for the quantity bound as silver chloride. Although the experiment was restricted to examination of fertilization processes due to time constraints, a number of trends in post-fertilization development were also observed. E. parma development from fertilization to the larval stage progresses quite rapidly and many of the eggs that did successfully undergo fertilization also began to divide during the course of data collection. The majority of zygotes exhibited the proper first division to two blastomeres under all treatment conditions. However, beyond this point notable variation in number of blastomeres present was observed across treatments. The majority of control embryos progressed from a two-cell stage to a four-cell stage and then an eight-cell stage. Conversely, embryos in the $10^{-3} \mathrm{M}$ treatment exhibited abnormal divisions, progressing from a two-cell stage to a three-cell stage and then a six-cell stage. Many of the blastomeres in these abnormal embryos appeared misshapen and often, the entire embryo would dissociate, with blastomeres dispersing into the medium. While not evaluated for significance, these observations invite further investigation. They are also in agreement with findings by Ward et al. that the percentage of normal Arbacia punctulata pluteii decreases in correlation to an increasing concentration of silver [7]. It should be noted that some studies have attributed abnormal echinoderm larval development to polyspermy and because this experiment did not employ sperm titration methods, there is a possibility that polyspermy contributed to the observations recorded here [18]. However, polyspermy would not account for the differences in larval development patterns between treatments; therefore future studies examining echinoderm development after silver exposure should employ sperm titration in order to confirm or refute the observations made in this experiment.

This study contributes to the growing body of evidence that silver is a highly toxic metal even at very low concentrations. As the EPA moves forward in revising silver ambient water quality criteria, the finding that the amount of silver required to reduce fertilization success in E. parma by $30 \%$ is less than current drinking water standards certainly warrants consideration. While further investigation of the physiology behind silver toxicity is required to fully understand the range of applications of invertebrate model research, it is apparent that regardless of mechanism, species or stage of life, the end result of silver exposure is consistently negative to the health and fitness of the organism.

\section{METHODS}

\section{Experimental Protocol}

This experiment used a sample of ten mature adult $E$. parma, five males and five females, collected from the intertidal zone at Bar Road in the Bay of Fundy, Canada. The sample was maintained at the Huntsman Marine
Laboratory in St. Andrews, NB under flow-through conditions in a 20 gallon aquarium containing filtered seawater at $10^{\circ} \mathrm{C}$. Spawning was induced by coelomic injection of $1 \mathrm{ml}$ of $0.5 \mathrm{M} \mathrm{KCl}$ in the mouth, in a direction parallel to the oral surface, as described by Tyler [16]. Individuals were placed aboral side down in $250 \mathrm{ml}$ beakers filled with $250 \mathrm{ml}$ of seawater at $10^{\circ} \mathrm{C}$ to elicit release of gametes. Following visual confirmation of spawning, individuals were transferred to finger bowls containing 100 $\mathrm{ml}$ of seawater at $10^{\circ} \mathrm{C}$ and gametes were collected directly from the gonopore via 5.75 inch Pasteur pipette. Sperm were stored in $1.5 \mathrm{ml}$ microcentrifuge tubes in ice baths at $4^{\circ} \mathrm{C}$. Eggs were stored in a $250 \mathrm{ml}$ beaker containing $50 \mathrm{ml}$ of water at $10^{\circ} \mathrm{C}$. After gently stirring to evenly distribute the eggs in solution, $1 \mathrm{ml}$ of egg was transferred into each of 5 wells in a 6 well culture plate containing $5 \mathrm{ml}$ of seawater at $10^{\circ} \mathrm{C}$ and at a concentration of $0 \mathrm{M}, 10^{-3} \mathrm{M}, 10^{-5} \mathrm{M}, 10^{-7}$ $\mathrm{M}$, or $10^{-9} \mathrm{M} \mathrm{AgNO}_{3}$ (Fisher Chemical, Toronto, ON). Eggs were incubated in treatment conditions for fifteen minutes prior to the addition of sperm. Sperm from all males were pooled and $10 \mu \mathrm{l}$ of sperm transferred into a $150 \mathrm{ml}$ beaker containing $100 \mathrm{ml}$ of filtered seawater at $10^{\circ} \mathrm{C}$. To initiate fertilization, $1 \mathrm{ml}$ of diluted sperm suspension was added to each of the wells. A minimum of twenty minutes after the addition of sperm, random $500 \mu \mathrm{l}$ samples from each well were examined under a stereomicroscope and percent fertilization calculated as the number of zygotes formed out of 100 eggs. Mean percent fertilization was calculated using three replicates of the control at each concentration of $\mathrm{AgNO}_{3}$ as per Ward et al. [7].

\section{Data Analysis}

Data have been expressed as means \pm 1 s.e.m. A oneway Analysis of Variance (ANOVA) was used to test for significance among treatments, followed by a Fisher's Least Significant Differences test for post-hoc comparisons of individual treatments. All tests were conducted using SPSS statistical software v.19.0.0, assuming significance at $\mathrm{p}<0.05$.

\section{REFERENCES}

1. Arizza, V., Di Fazio, G., Celi, M., Parrinello, N. and Vazzana, M. (2009). Cadmium, copper and tributyltin effects of fertilization of Paracentrotus lividus (Echinodermata). Ital. J. Anim. Sci. 8, 839-841.

2. Chase, M. E., Jones, S. H., Hennigar, P., Sowles, J., Harding, G. C. H., Freeman, K., Wells, P. G., Krahforst, C., Coombs, K., Crawford, R., Pederson, J. and Taylor, D. (2001). Gulfwatch: Monitoring spatial and temporal patterns of trace metal and organic contaminants in the Gulf of Maine $(1991 \pm 1997)$ with the blue mussel, Mytilus edulis L. Mar. Pollut. Bull. 42, 491-505.

3. Westgate, A. J., Muir, D. C. G., Gaskina, D. E. and Kingsley, M. C. (1997). Concentrations and accumulation patterns of organochloride contaminants in the blubber of harbour porpoises, Phocoena phocoena, from the coast of 
Newfoundland, the Gulf of St. Lawrence and the Bay of Fundy/ Gulf of Maine. Environ. Pollut. 95, 105-119.

4. Powers, C. M., Yen, J., Linney, E. A., Seidler, F. J. and Slotkin, T. A. (2010). Silver exposure in developing zebrafish (Danio rerio): Persistent effects on larval behavior and survival. Neurotoxicol. Teratol. 32, 391397.

5. Bianchini, A., Playle, R. C., Wood, C. M. and Walsh, P. J. (2005). Mechanism of acute silver toxicity in marine invertebrates. Aquat. Toxicol. 72, 67-82.

6. Bond, A. L. and Diamond, A. W. (2009). Mercury concentrations in seabird tissues from Machias Seal Island, New Brunswick, Canada. Sci. Total Environ. 407, 4340-4347.

7. Ward, T. J., Kramer, J. R., Boeri, R. L. and Gorsuch, J. W. (2006). Chronic toxicity of silver to the sea urchin (Arbacia punctulata). Environ. Toxicol. Chem. 25, 15681573.

8. Naddy, R. B., Gorsuch, J. W., Rehner, A. B., McNerney, G. R., Bell, R. A. and Kramer, J. R. (2007). Chronic toxicity of silver nitrate to Ceriodaphnia dubia and Daphnia magna, and potential mitigating factors. Aquat. Toxicol. 84, 1-10.

9. Ratte, H. T. (1999). Bioaccumulation and toxicity of silver compounds: a review. Environ. Toxicol. Chem. 18, 89108.

10. U. S. Environmental Protection Agency. (1999). Notice of intent to revise aquatic life criteria for copper, silver, lead, cadmium, iron and selenium. Federal Register. 64, 58409-58410.
11. Aluigi, M. G., Falugi, C., Mugno, M. G., Privitera, D. and Chiantore, M. (2010). Dose-dependent effects of chlorpyriphos, an organophosphate pesticide, on metamorphosis of the sea urchin, Paracentrotus lividus. Ecotoxicol. 19, 520-529.

12. Bailey, H. C., Miller, J. L., Miller, M. J. and Dhaliwal, B. S. (1995). Application of toxicity identification procedures to the echinoderm fertilization assay to identify toxicity in a municipal effluent. Environ. Toxicol. Chem. 14, 2181-2186.

13. Crawford, R. B. and Gates, J. D. (1981). Effects of a drilling fluid on the development of a teleost and an echinoderm. Bull. Environm. Contam. Toxicol. 26, 207212.

14. Wood, C. M., Hogstrand, C., Galvez, F. and Munger, R. S. (1996). The physiology of waterborne silver toxicity in freshwater rainbow trout (Oncorhynchus mykiss) 1. The effects of ionic Ag+. Aquat. Toxicol. 35, 93-109.

15. Flegal, A. R., Sanudo-Wilhelmy, S. A. and Scelfo, G. M. (1995). Silver in the eastern Atlantic Ocean. Mar. Chem. 49, 315-320.

16. Tyler, A. (1949). A simple, non-injurious method for inducing repeated spawning of sea urchins and sanddollars. Coll. Net. 29, 19-20.

17. Gopalakrishnan, S., Thilagam, H. and Raja, P. V. (2007). Toxicity of heavy metals on embryogenesis and larvae of the marine sedentary polychaete, Hydroides elegans. Arch. Environ. Contam. Toxicol. 52, 171-178.

18. Ernst, S. G. (1997). A century of sea urchin development. Am. Zool. 37, 250-259. 